\title{
Computational Uses of Philosophical Dialogue Theories
}

\section{DAVIDMOORE \& \\ DAVEHoBbes}

\begin{abstract}
The research discussed in this paper concerns an investigation of logical dialogue games as a vehicle for enhanced human-computer communication. The need for a dialogue capability in computer systems is argued, and a prima facie case made for dialogue games, in particular Mackenzie"s "DC", as a suitable dialogue model. Empirical work concerning DC is outlined, and strategies for adoption by the computer are presented. A user interface, software architecture and conceptualised example are discussed. The hope is that the paper will help bring together two groups of workers philosophers of dialogue and designers of computer systems-to the mutual benefit of each.
\end{abstract}

\author{
Leeds Metropolitan \\ University
}

Résumé: La recherche discutée dans cet article porte sur l'investigation des jeux de dialogue logique employés pour faciliter la communication humaine avec les ordinateurs. On soutient que l'aptitude au dialogue des systémes informatiques est6 un réel besoin et qu'à première vue les jeux de dialogue y répondent. En particulier, le "DC" de Mackinzief semble offrir un modèle approprié de dialogue. On trace les grandes lignes des recherches empiriques sur le DC et l'on propose des statégies pour l'appliquer aux ordinateurs. On discute de l'interface pour l'usager, de la configuration du logiciel et d'un exemple conceptualisé. On espère que cet article encouragera un rapprochement mutuellement avantageux entre deux groupes de travailleurs: les philosophes du dialogue et les concepteurs des systèmes informatiques.

Keywords: logical dialogue games, DC, Intelligent tutoring systems

\section{Introduction}

The aim of this paper is to alert people working in what can be called the philosophy of dialogue (Walton 1989) to computational utilisations of theoretical insights gained in this field, and hence perhaps to pave the way towards a fruitful collaboration between the fields. The paper will therefore start by arguing the need for a dialogue capability within interactive computer systems. It will then outline some of the diffi- 
culties engendered by attempting to provide dialogue, and briefly review the theoretical foundations of some of the attempts to address these difficulties. Since the particular interest of the current authors is in the utilisation of logical dialogue games, in particular the system "DC" (Mackenzie 1979a), our work in these areas will be presented in rather more detail in the remainder of the paper.

\section{The need for dialogue within interactive computer systems}

The ubiquity of the computer, and the corresponding advent of end-user personal computing, has made it vital that end-users are able successfully to operate the systems with which they are working; failure or refusal to do so can mean a lack of satisfaction for the user, and of success for the system. This is the problem which the field of Human Computer Interaction (HCI) seeks to address (e.g., Shneiderman 1992). One area which receives much attention is that of dialogue design. Despite some terminological confusion in the area (Booth 1989), it is safe to say that dialogue design encompasses two broad issues. The first concerns the manner in which the user will interact with the machine, whether, for example, they will be presented with a menu of options, a command line interface, or some form of question-answer interaction. The second area concerns the attempt to emulate dialogue of the sort engaged in by human conversants, in which topics of mutual concern are discussed, and in which each conversant has substantive points to make; the interest is in the content and form of the dialogue, rather than the manner of its physical implementation. It is the second area with which we are chiefly interested.

One type of interactive computer system which would benefit greatly from such dialogue is a computer based learning (CBL) system. Whilst it is not without its critics (e.g., Ridgway 1988), the use of CBL in education offers advantages in terms of progressing at the pace of the individual student and of allowing the student to experiment and interact without the fear of ridicule from his tutor or peers (Mushrush 1990), and of enabling learning to be customized to the needs of the individual student (ElsomCook 1988). As O'Shea and Self (1983) put it, the aim is for each student to have their own Aristotelian tutor. A dialogue capability should be seen, it can be argued, as a fundamental part of such systems (cf. Baker 1994). For the importance of discussion and debate in education is frequently stressed at primary (e.g., National Curriculum Council 1990a), secondary (e.g., National Curriculum Council 1990b), and tertiary (e.g., Garrison 1991) levels. And this, together with the practical difficulties of facilitating one-to-one discussion in education (e.g., Galton and Simon 1980), suggest great potential for CBL systems to make a major practical contribution in this regard. This in turn suggests a need for interactive dialogue in such systems.

Another type of system that would benefit from such dialogue is the so-called "expert system" (e.g., see Jackson 1990). These systems seek to encapsulate expert knowledge about some typically constrained domain, and to engage with users in "consultation dialogues" (Bench-Capon 1990) with a view to solving specific problems 
within that domain. An explanation facility is regarded as an important component of expert systems, but current provision has been criticised as being hard for users to understand, verbose, and not matched to the users' expectations or prior knowledge, and "interactive argument" has been proposed as a more useful model of interaction (Bench-Capon et al. 1991). Another type of system which would benefit from dialogue capability is the on-line help system. Empirical work connected with the EUROHELP project, for example, showed that more than two-thirds of answers to help queries were followed up with further queries, conjectures, or counter-assertions, clearly suggesting the need for dialogue (Pilkington 1992a).

\section{The Dialogue Management Problem}

It has turned out to be very difficult to emulate dialogue computationally, and there is a great need for further research: "There remains a substantial amount of foundation work to be done in order to make extended models of conversation that are both computationally tractable and formally sound" (Finkelstein and Fuks 1990). A natural point of departure for such foundation work is research involving human dialogue (Girle 1986). The issue of how humans conduct dialogue is, however, itself highly controversial. Shiffrin (1985), for example, claims that discourse analysis is "so internally differentiated that its practitioners [fail] to recognise any common core".

This controversy is, as one might expect, reflected in current attempts to build computational dialogue systems (cf. Stenton 1988). Reichman (1985), for example, has devised a system in which discourse is characterised as a hierarchical organisation of related types of utterances. A "context space" is delineated together with a specific set of conversational moves in that space, such as "support" or "conclusion". A set of discourse rules have been developed, which seek to transform Gricean maxims into a set of operational rules governing the interpretation and generation of "maxim-abiding" conversation.

Reichman is explicitly opposed to basing computational systems on conversational analysis. Frohlich and Luff (1990), on the other hand, do seek to ground a dialogue system on ethno-methodological concepts, and claim that such a model "will prove more appropriate than any other for the design of human-computer conversations". Adopting what might be seen as an intermediate position, Cawsey (1990) utilises ideas from both conversation and discourse analysis, and Finkelstein and Fuks (1990) seek to integrate work from what are often seen as the contending approaches of conversation analysis and discourse analysis.

Levin and Moore (1977, cf. Mann 1988) claim to have empirically identified several dialogue games, conceived as identifiable types of "systematic interaction" in which conversants engage. These games are used as the basis for a computational "process model" of the comprehension of dialogue utterances, and are also used by Elsom-Cook (1985) and Baker (1989) in their intelligent tutoring systems in the realms of, respectively, the programming language LISP, and music. 
Carlson (1983, 1984a, 1984b) develops a complex theory of idealized conversation. Carlson speculates as to the utility of the theory in computational contexts, and the model has in fact been used as the basis for the implementation of the intonation interpretation module of a speech-understanding system (Hoepelman et al 1991), though it is admitted that "the dialogue model and the dialogue rules are still very preliminary".

There is, then, a plethora of approaches to computational dialogue, each grounded to some extent on an underlying theory of human discourse. In our current research we have adopted the policy, rather than await the resolution of the controversy, of selecting a discourse model and putting its potential to the test. If the dialogues generated as a result of its use are deemed to represent satisfactory dialogue, and thus to offer an improvement over current facilities, the model will be deemed to that extent successful. If not, the model will be deemed to that extent unsuccessful. The model to be adopted is derived from work on "logical dialogue games" (e.g. Walton 1984). The central claim to be investigated in our research, therefore, is that such games can provide a suitable framework for a computer-based dialogue system. For this claim to be of interest and hence worthy of investigation, there should be some prima facie case for the adoption of such games. This case will be made in the next section.

\section{Logical dialogue games}

What will here be referred to as "logical dialogue games" in fact have a range of different nomenclatures in the literature, such as "formal games of dialogue", "logical structures", "dialectical games" (Walton 1984), and "dialectical systems" (e.g. Hamblin 1987, Mackenzie 1979b). The games are also defined in somewhat different ways. Hamblin (1971) defines a dialectical system as a triple $\angle P, L, K>$, where $P$ is a set of participants, $\mathrm{L}$ a set of locutions, and $\mathrm{K}$ a set of legal dialogues defined within a dialogue by a set of rules. Mackenzie (1979b) defines a "dialectical system" as a triple $\langle P, L, R>$, where $P$ is a set of participants, $L$ a set of locutions, and $R$ a set of rules which define a set $K$ of legal dialogues. Walton (1984) suggests that within the framework of a logical dialogue game, an argument can be seen as a set of locutions, indexed to a participant in the game, where the participant may advance a locution only according to certain dialogue rules; he then defines a dialectical system as such a game, with the addition of a "strategic component defining win-loss requirements" (Walton 1984). Elsewhere (1989) he suggests, in a definition reminiscent of Hamblin's, that " a game of dialogue is a triple: (1) a set of players, (2) a set of moves, (3) a set of rules". The names and definitions are somewhat different from each other, therefore, but the general notion is clear: a logical dialogue game is a set of rules, regulating the participants as they make moves in the dialogues. These rules will legislate as to permissible sequences of moves, and also as to the effect of moves on participants' "commitment stores", conceived as records of statements made or accepted. 
The motivation behind the development of such games is that the study of argumentation in such contexts will supplement apparent defects in the application of formal logic (Walton 1985, Barth and Martens 1982). In particular, the concern is in many cases with modelling (and hence helping to avoid) fallacious argumentation. Thus Girle (1986): "When a dialogue becomes illegal, so the theory goes, fallacies occur". An implication of this is that, despite some apparent ambivalence with regard to the status of the theory (cf. Moore 1993), it can be seen as a prescription for reasonable, rather than descriptive of actual, dialogue: "... at one level ... the pragmatics of dialogue involves the prescriptive study of what is fair and reasonable in argument and criticism" (Walton 1985, cf. Finkelstein and Fuks 1990).

Logical dialogue games, as so characterised, have a number of apparent attractions from the point of view of their utilisation within a computer dialogue system. First, given that the games purport to be models of "what is fair and reasonable in argument and criticism" (Walton 1985), then constraining both computer and user to such a game will, if the game is valid, yield "fair and reasonable" dialogue, and thus satisfy the desiderata discussed in section 2 . A second part of the case for the adoption of logical dialogue games relates to claims made for their educational advantages. Walton, for example, suggests that "the circular staircase of dialectic can be an assent out of the cave of fallacy, from the darkness towards the light" (Walton 1984), and Hartley and Hintze (1990) suggest as educational advantages of a logical dialogue game approach within CBL that the student can probe and question the tutor, and express his own viewpoint.

A further argument is that the discipline imposed on players by the games is likely to make more tractable the task of providing for dialogue via machine. Several factors contribute to this likelihood. The first concerns the notion of dialogue rules. The aim would be to utilise these generic rules to establish the legality of student input, and to assist in formulating a response by restricting attention to the set of legal moves, and thus to guide the dialogue beyond a single question/answer interaction. The computational attractiveness of the dialogue game rules is enhanced by a consideration of their nature. For the rules of logical dialogue games are characteristically tight; Mackenzie's (1979a) rules, for example, prescribe no more than three types of responses to an incoming move type, thus promising to ease the task of checking for legality, and to reduce both the search problem for the computer's rejoinder and the strategic issue of selection between competing alternatives.

The games' concern with modelling commitment rather than belief is also attractive from a computational perspective. Commitments are incurred during the dialogue, in line with clearly stated commitment rules, and the resulting "commitment store" is seen not as a psychological model of memory, but rather as akin to a publicly inspectable set of statements recorded on a slate (Mackenzie 1979a, Hamblin 1970). This separation of commitment from belief has the advantage that one can allow for machines to argue without having to concede that they have beliefs (Mackenzie 1979a). Equally important, the explicit nature of the commitment function intuitively suggests computational feasibility. 
The characterisation of dialogue moves also appears advantageous from the computational point of view, for several reasons. First, the content of a move is generally restricted to one "locution", i.e. a statement together with a statement operator (e.g., assert, question, withdraw). Although this length restriction has the consequence that certain dialogues, e.g., the cannibalism dialogue of Woods and Walton (1982a), cited approvingly by Walton himself (1989), would fall outside the scope of such systems, it has the computational advantage of avoiding complexities such as deciding on a practical length for turns (Clark and Schaefer 1989), or formulating a turn-length control policy (Frohlich and Luff 1990), and difficulties involving moves spanning more than one speaker turn (Reichman 1985).

Further, the restricted range of move types allowed by the games potentially makes it possible to use a menu scheme for user input. In addition, the rule bound nature of the moves enables relatively straightforward checks on the legitimacy of input. The strictures of the rules can be expressed as move type pre- and post-conditions, and this suggests the possibility of autonomous move type objects which have an awareness of their own availability at certain stages of the game, and also of internal consistency checks between the currently applicable rule and the currently satisfied preconditions.

Perhaps the main computational attraction, however, is the clarity and expressiveness provided by the moves. Their pre-and post-conditions relate purely to explicit moves and to participants' (inspectable) commitment stores, so that complications concomitant upon implicit moves never arise. Neither is there any requirement to attempt the difficult task of divining the intentionality of the maker of the move (cf. Reichman 1985, Mackenzie 1990), given the move's clearly defined function within the game. Intentionality is, in effect, embedded within the move. The difficulty of interpreting pragmatic content is, therefore, largely overcome: "the idea would be to limit formally the permissible forms of expressions so that intention in utterance would be unambiguous and the need for complex pragmatic parsing would be bypassed" (Pilkington 1992a).

Thus moves and commitments are clear, and dependent only upon the locution used (Mackenzie 1979a) so that issues of illocutionary force, for example (Stenton 1988), are by-passed, as are "dynamic social-psychological factors" such as politeness (Reichman 1985). The possible loss of richness consequent upon this can be seen simply as a reflection of the different paradigm that computer-based communication offers, and greatly improves the prospects for successful computer implementation (cf. Pilkington 1992a).

Further support for the approach's computational tractability can be found in the literature. It is seen by Girle (1986, cf. Stewart-Zerba and Girle 1993) and Hartley and Hintze (1990) as a potential means of widening the communication channel of CBL systems. Bench-Capon et al. (1991) see dialectic as a useful model of interaction with a knowledge-based system, and utilise a dialogue manager incorporating a Mackenzie-style dialogue game. Finkelstein and Fuks (1990) also favour the adop- 
tion of a Mackenzie-style dialogue game, enriched with certain concepts drawn from ethnomethodology, as the basis for a system for providing automated support for developing software specifications. Fuks et al (1989) seek to use a Hamblin-style approach to dialogue to provide automated support for legal reasoning, and Jeremaes (1987) to use dialogue games to characterise a logic of interaction. Dialogue game theory (DGT) is seen as a potentially useful addendum to the intelligent help system "EUROHELP" (Hartley et al 1990), and Bailey (1989) suggests the possible use of DGT to extend user interactions with her explanation-driven medical expert system. More generally, Gordon (1994) uses a Lorenzen-style dialogue game to implement a computational model of civil pleading, and speaks of "Computational Dialectics" as a new subfield of Artificial Intelligence.

There are, then, a number of convincing reasons for the adoption of logical dialogue games as the basis for the dialogue model in a computer dialogue system. There are also a number of factors that have been explored with regard to the design of such games, concerning the appropriate rule set, the nature of commitments, and whether the games should be competitive (see Moore (1993) for a discussion of these design parameters). Given these various design parameters, it is not surprising, perhaps, that a large number of alternative dialogue game systems have been proposed. Walton (1984), for example, discusses some 15 different games, and Barth and Krabbe (1982) describe a dozen or so others. The issue, as far as a computer-based dialogue system is concerned, therefore, would be one of deciding which of the various game types would be the most appropriate as a vehicle for the system. The game type currently forming the focus of our research will be discussed in the next section.

\section{The game "DC"}

For the purposes of the current research, a (somewhat modified version of) Mackenzie's dialectical system "DC" (Mackenzie 1979a) has been adopted. The system allows 5 move types: statement ('P', ' $Q$ ' etc., and their truth functional compounds), withdrawals (e.g. 'no commitment to P'), questions ('is it the case that P?'), challenges ('why is it held that P?'), and resolution demands ('resolve whether P'). There are 4 rules regulating commitment stores: stores are null at dialogue commencement; statements by either participant are added to the stores of each; a statement $P$ in response to a challenge of $Q$ results in both $P$ and $P \longrightarrow Q$ being added to each store; a challenge of $P$ results in $P$ being added to the store of the hearer, and $P$ being removed from, and why-P being added to, the store of the maker of the move.

There are 6 dialogue rules in our amended version of the system (see Moore (1993) for a discussion of the amendments): participants may utter individual permitted locutions in turn ( $\left.\mathrm{R}_{\text {FORM }}\right)$; mutual commitments may not be uttered $\left(\mathrm{R}_{\mathrm{REPSTAT}}\right)$; the question $P$ ? must be answered by ' $P$ ', 'not $P$ ', or 'no commitment $P$ ' $\left(\mathrm{R}_{\text {Quest }}\right)$; 'why P?' must be responded to by a withdrawal of ' $P$ ', a statement not under challenge by its speaker, or a resolution demand of any commitments of the hearer which immediately imply ' $P$ ' $\left(R_{\text {CHALL }}\right)$; resolution demands may be made only if the hearer is com- 
mitted to an immediately inconsistent conjunction of statements, or withdraws or challenges an immediate consequent of his commitments $\left(R_{R E s O L V E}\right)$; a resolution demand must be followed by withdrawal of one of the offending conjuncts, or affirmation of the disputed consequent $\left(\mathrm{R}_{\mathrm{RESOLuTiON}}\right)$.

The notions of immediate consequence and immediate inconsistency are defined by Mackenzie with the help of a list (V) of "preferred valid argument schemata" (1979b), i.e., "argument patterns immediately recognised as valid by the participants" (Mackenzie 1990). Immediate consequence consists of an instantiation of one of the schemata. Immediate inconsistency consists either of a statement together with its denial, or of a set of statements $Z$, together with the denial of an immediate consequence of $Z$. The contents of $V$ are, according to Mackenzie (1979b), to be discovered by empirical observation of language-conditionals which participants in dialogue regard it as "bizarre" to deny or doubt are examples of immediate consequence conditionals, and V is built up from a study of participants" "bizarreness reactions" (Mackenzie 1990).

This, then, is, in outline, the (amended) system "DC". The reasonableness of the adoption of this system can be argued for partly on negative grounds. For our initial aim is to utilise DC as the dialogue model in a computer system providing for educational debate, in which the computer will take up a position on a controversial issue diametrically opposed to that of the student, and engage the student in debate on that issue; this, it is held, may foster the student's debating skills and level of critical awareness, and make him more aware of the substantive issues involved (Moore 1993). And other documented systems within the logical dialogue games field appear not to be entirely appropriate for this role (Moore 1993). In particular, the Lorenz approach (Lorenz 1982, 1987) is argued to be asymmetric and overly deterministic, the Barth and Krabbe (1982) approach to be hard for the student to master and not directly applicable to debate, and the Hintikka approach (Hintikka and Hintikka 1982) to be biased towards the questioner. There are, it is argued, conceptual difficulties with the dark-side commitment set on which many of Walton's systems are based (e.g., Walton 1989), and Mackenzie's work is widely seen to represent a step forward from the Hamblin games upon which it is based. This is not to deny the general worth of these other systems, merely to suggest that they may not be appropriate for the specific requirements of a computer-based debating system.

More positive arguments for the adoption of DC can also be cited. Walton (1984) argues that "the design of the rules appears practically useful", by enabling participants to enforce a "certain surface rationality in the opponent's commitment store", without requiring omniscience vis-à-vis the consequences of the commitments; this reflects Mackenzie's own view that "people are not perfect logicians" (1985). Mackenzie claims to give DC a "more rigorous formulation" than given previously to systems used in the solution of fallacies (1979a), and that his treatment of resolution demand goes beyond that of Hamblin (Mackenzie 1985). 
The rules of the system are clear, and little knowledge is needed to apply them. In order to assess the legality of an event within a dialogue, it is necessary to know only the state of the commitment stores, the previous event, and the "syntactic relations between locutions" (Mackenzie 1979a). This simplicity of the rules is also important from the educational point of view. For a pre-requisite of the educational use of such a system is that students are able to adopt its prescriptions with a minimum of cognitive difficulty, and whilst the degree to which this pre-requisite is in fact met by DC is an empirical question, it can at least be claimed on an a priori basis that its relative simplicity makes the issue of DC's suitability worthy of empirical study.

Further, certain educational advantages can be claimed for DC, were it in fact to meet the pre-requisite of ease of use. The game is symmetric (Mackenzie 1985), so that both parties to it have the same rights and obligations, and may have to defend their own position. This means that the tutor can build its own position (cf. Pilkington et al 1992), thus making the student consider views of which he was perhaps previously unaware; indeed, the two-way commitment rules of the system prevent the student from simply ignoring the views of the tutor (and vice-versa). A further implication is that the student is allowed to challenge the tutor's position. This enables him to receive different explanations of that position (Finkelstein and Fuks 1990), and to cease to regard the tutor's views as indisputable.

The game symmetry also implies that the student will be able to build a position himself. Thus student initiative can be catered to, and the student will be required to be consistent and to face the consequences of what he says (cf. Mackenzie 1981). He will also be required to support (give reasons for) views he puts forward, and in so doing may deepen his understanding of his adopted view by discovering hitherto "suppressed" premises (Mackenzie 1979a). Commitments of both parties are made clear by the commitment rules, and since at any stage the number of entries in a store is at most twice the number of moves made to that stage in the dialogue, combinatorial explosions of commitments cannot occur (Mackenzie 1990). The system is non-cumulative (Mackenzie 1979a), so the student is able to withdraw commitments he no longer wishes to adhere to, and to give non-committal responses to questions to which he does not know the answer. Since there is no defined end-point to the game in terms of, for example, maximum number of moves, the game can end in a draw, thus reflecting both the fact that educationally worthwhile interaction can take place without one party winning the debate (Moore 1993), and Walton's view that "agnosticism should be permissible in reasonable dialogue" (1989).

As well as these general arguments for the adoption of DC, it is also possible to point to certain precedents for its use in a computational context (see Bench-Capon et al (1991), Hartley and Hintze (1990), and Finkelstein and Fuks (1990)). As a final plank in the case for adoption of DC, it is worth giving an example of the sort of dialogue that participants can produce by the use of the system. The following hypothetical example from a medical context is based on a dialogue cited in Pilkington et al. (1992): 

A: A diuretic is the appropriate treatment.
B: Why?

A: You have said that the symptoms include low blood pressure, high pulse, and low central venous pressure, and that if these systems occur together then heart failure is a likely candidate.

B: You are suggesting that a diuretic is a suitable treatment for heart failure?

A: Yes.

B: Is the patient's fluid intake for the last six hours normal?

A: No.

$\mathrm{B}$ : Is the fluid intake low?

A: Yes.

B: If the fluid intake is low, then the symptoms could be caused by fluid imbalance.

A: Fluid imbalance is an alternative but less probable candidate.

$B$ : Is it not the case that if you were to give a diuretic and the cause of the symptoms is fluid imbalance, then the patient's condition would worsen?
A: Yes.
B: Why?

A: A diuretic would cause further dehydration.

B: So, you agree that a diuretic is not necessarily the best treatment?

Other examples can be found in Finkelstein and Fuks $(1989,1990)$, Hartley and Hintze (1990), Moore (1993) and (Mackenzie 1984). Such dialogues are realistic and of potential educational benefit to the users. The practicality of such dialogues, both from the point of view of students successfully adopting the dialogue model (DC) and from the point of view of having a computer act as a partner in them, is the major issue of our current research.

There is therefore much to be said for the proposal to adopt DC. This is not to say, however, that there are no weaknesses with the system. Indeed, a range of potential weaknesses are discussed in (Moore 1993). One problem highlighted by Mackenzie himself concerns the cumulative nature of challenges, for it has been argued (Woods and Walton 1982b) that it erroneously bans certain sequences of moves as question begging (cf. Mackenzie 1984). The best technical solution may be to allow, in response to a challenge, statements which though once under challenge have been subsequently uttered by the challenger, but this was rejected for the initial prototype on the grounds that it was likely to cause undue complexity.

\section{Assessing the utility of $\mathrm{DC}$ within a computer dialogue system}

The proposal therefore is to adopt an amended version of DC as the framework for the putative computerised dialogue system. In order to assess the validity of this proposal, it is necessary to establish whether DC offers a computational model of dialogue. It is necessary to ask therefore first whether DC is a satisfactory model of 
dialogue at all, and, second, whether the model is computationally tractable.

The nature of the first enquiry is largely determined by the status of DC, which will be taken as a prescriptive model. Given this status, one thing that needs to be shown is that people are able to adopt and use the prescriptions to generate dialogue. This general requirement of prescriptive models, echoed by Walton (1989) in his talk of rules being clear and simple enough to be agreeable to both participants, is particularly important in both education (for to be educationally viable the prescriptions must not be too cognitively taxing), and in a computational context (for a user must be aware, for example, of the significance of the menu items from which he may select). Whether this requirement in fact is met by DC is not something that can be settled on an a priori basis. It may turn out, for example, that the rules are overly complex, standing in the way of, rather than facilitating, the generation of useful argument.

If people are able to adopt the prescriptions, it then needs to be shown that the resulting dialogue can be considered "fair and reasonable", in a sense to be discussed later. This question also needs to be settled empirically. For the issue of interest is not whether a philosophical expert could manipulate the rules in such a way as to generate dialogue which is not fair and reasonable (e.g. dialogue which is fallacious). The issue is, rather, whether, even if unfair dialogue can in principle be generated, it is in fact generated in practice. The claim, if upheld, will show only that DC tends to generate fair and reasonable dialogue; the stronger claim that only DC can generate such dialogue will not of course be demonstrated.

Whilst the truth of the stronger claim is not needed to justify the system's computational use, some cognisance does need to be taken of the properties of the dialogue resulting from use of $\mathrm{DC}$ as compared with those of naturally occurring dialogue. Simply to show the dialogue is fair and reasonable is not enough, for it may differ from unconstrained dialogue in ways which are not acceptable. To draw an analogy with another prescriptive field, a medical cure will be rejected if it causes unacceptable side-effects, even though it may cure the original illness.

Again, this issue cannot be settled on an a priori basis, and a comparison of DCgenerated dialogue with unconstrained dialogue will be required. This comparison will be important in its own right, and also in relation to the trade-off between the cognitive effort of adopting the DC regimen, and the gains accruing from so doing, for the less satisfactory the comparison is judged to be, the less advantageous the trade-off will become. Carlson (1984a) suggests that computational models of dialogue may involve strong simplification and regimentation of ordinary human conversation, and the current enquiry may be revealing vis-à-vis the acceptability of such regimentation in the case of DC. It is important to remember, however, that the purpose of the comparison is not to establish whether DC emulates ordinary dialogue, since it is seen as a different paradigm - cf. Barth and Krabbe's point (1982) that their rules are not intended to mirror just everything that happens in debate. The point is, rather, to seek to establish the acceptability of any alterations from ordinary conversation which may be induced by adherence to the $D C$ regimen. 
If it is shown, as a result of the enquiries just outlined, that people are able to use DC to generate dialogue which is fair and reasonable and not unduly constrained in comparison with natural dialogue, then this would both provide supporting evidence of the validity of the model, and sanction the use of the game rules as the prescriptive basis for the human-computer interaction. For such interaction to be viable, it needs to be shown, further, that the framework offered by DC is computationally tractable. It needs to be shown, in particular, that a computer is able to use the rules to regulate debate; for the computer actually to participate in debate it would also need to be shown that sufficient strategic and semantic wisdom can be given to the machine, since DC operates at a very high level of abstraction. An affirmative finding would mean that the educational advantages discussed in Section 2 can potentially be achieved. It would also illuminate Mackenzie's claim (1981) that machines may be able to participate in dialogue and add to Barth's claim (1982) that dialectical systems are of practical as well as philosophical value.

The broad questions requiring to be investigated, therefore, are first whether the $\mathrm{DC}$ regimen is a valid prescriptive model of dialogue, and second whether the system is computationally practical.

There are, however, at least two difficulties that might be raised against this proposed enquiry. First, Anastasi (1982) reports the view that, given appropriate instruction, virtually anyone can achieve mastery of any instructional objective. Applying this to the current proposal, it might be argued that the issue of whether people can learn $D C$ is vacuous, for the answer will inevitably be in the affirmative. What matters, though, is the ease and readiness with which the regimen can be adopted, rather than whether it could in principle be taught to everyone, for this will affect the relative advantage afforded by the system at the user interface. The question is not, therefore, vacuous.

Second, it might be said that a negative answer to the enquiry will never be reached, for undue difficulty in adopting the prescriptions, and/or failure to generate satisfactory dialogue, would indicate merely defects in the system used, rather than the failure of DGT as such. Whilst this is true in general, and may represent a difficulty endemic to research in educational technology, the criticism misses the point in the current context, where the aim is precisely to establish the suitability or otherwise of $\mathrm{DC}$, as a prima facie reasonable system, with precedents for its usage. A negative answer would therefore be significant, though it would remain possible for another system to be found suitable.

\section{Empirical work concerning DC}

\subsection{DC as a practical dialogue model}

The issue of the extent to which and the readiness with which would-be dialogue participants are able to understand and put into practice DC has been addressed by an experiment, to be referred to as the "DC experiment", which was conducted in three 
stages - training, dialogue and debrief. The training session involved (i) explaining the rules of the game, (ii) holding and taping a brief (verbal) practice dialogue between experimenter and subject, and (iii) debriefing this session. The dialogue itself was held using remote terminals, in an attempt to simulate to some degree the environment in which the dialogue system might eventually be used. Each subject was allotted, on an arbitrary basis, one of the propositions "capital punishment should be re-introduced" or "capital punishment should not be re-introduced", and told to try to convert their partner to this position. Subjects were told that their partner held the contrary position, and would be attempting a similar conversion. It was stressed that, whilst their position might not reflect their genuinely held belief, they should nevertheless genuinely seek to convert their partner. The debrief took place immediately after the debate, and involved written answers to a short questionnaire containing open questions. Data arising from the DC experiment was analysed to seek to establish the extent to which, and the ease with which, users can adopt the prescriptive framework of DC. This was achieved by matching the data against four specific criteria.

The first concerns user understanding of the DC move types. On the majority of occasions subjects were found to classify correctly the moves made, suggesting that their view of what they are doing is generally consonant with the model's. Thus a low error rate can be predicted if users were presented with a menu of move types in a computerised version of the game. Subjects appeared to have most difficulty with the challenge move type, the only other difficulty of any significance concerning the resolution demand, which was occasionally incorrectly used. As a result of these localised difficulties, the dialogue game interface eventually developed (Hartley and Hintze 1990, see Section 8, below) adopts a menu system involving the DC locution modifiers (e.g. "I assert that...", "why...?"), rather than a command line interface or a menu interface involving the move type names. Further, the system displays the name of the move-type corresponding to user selection, enabling the user to check the accuracy of selection before "despatching" the move.

The second criterion concerns how far users can utilise the move types in accordance with the dialogue rules. The data suggests an overall picture of relatively infrequent rule breaks. Since all cases represent subjects' first exposure to the DC system, this seems an encouraging result from the point of view of using DC for computerbased dialogue. Further, analysis of the nature of the rule breaks suggests that most would be avoided in a computational context by proffering to the user only legally available move types and contents, thus enforcing legality on the user. This would further reduce the already limited incidence of rule transgressions.

The third criterion concerns the extent of subjects' appreciation of the effects of moves on their commitment stores. Subjects were not required to keep a running record of their commitment stores (CS), but rather to indicate as an answer to a debrief question what they believed their own and their partner's CS to contain. The evidence suggests that participants have major difficulty recalling the contents of their respective stores. No subject accurately reported the state of the CS, and some 
were explicitly concerned about the difficulty of CS retention. It needs to be stressed, however, that the store is intended as a public and inspectable record of commitments rather than a memory test. This fact, together with the cognitive difficulties of unaided CS recall brought to light by the DC experiment, led to the eventual incorporation of a CS "window" into the DC interface, displaying the respective participants" stores.

The fourth criterion concerns the extent of any learning difficulties. This is a crucially important criterion, since were the system to impose too great a cognitive burden on the participants, it would hinder rather than facilitate the debate, and thus achieve the opposite effect to the one intended. Some instances can in fact be found of possible learning difficulties on the part of the subjects. A number of concerns were voiced by subjects in connection with mastery of DC's rule set, suggesting that it would be hard to remember the rules. On the other hand, the generally successful manner in which subjects used the system, as indicated by the discussion of criteria 1 and 2 , may be taken as supporting the notion that the system is learnable within a relatively short time scale, and the DC interface (Section 8) attempts to ameliorate any learning difficulties by giving an explanation of the nature of any rule transgressions, and making a copy of the rules available on-line.

In sum, the data has suggested that people are generally successful in adopting the DC framework, and that the cognitive load it imposes is relatively light. Subjects have understood the move types well, rule breaks have been infrequent, and many of those that did occur could have been avoided with the aid of computational administration of the debate. Although there is some evidence of difficulty of mastering the DC framework, the cognitive load imposed by the need for such mastery would be considerably diminished via computational management of the dialogue framework, and seems unlikely in any event to be such as to stand in the way of the production of educationally valuable dialogue. Acceptance of this last point is contingent upon an evaluation of the dialogue produced by the use of DC. This issue will now be considered.

\subsection{Qualitative evaluation of $D C$ dialogues}

It is necessary, then, to conduct a qualitative assessment of the dialogue generated by the DC experiment. A further requirement is a comparative study involving the DC dialogues and dialogues generated by participants operating without DC-imposed constraints. For it may be that the attempt to exploit the formal properties of the DC framework causes unacceptable alterations, such as undue impoverishment, to normal conversation. Bench-Capon et al (1991) argue, for example, that because DC is a very formal system, adherence to its rules may result in a "somewhat stilted dialogue", and Mackenzie himself suggests that none of his games is "adequate" for "real life" argumentation (1990). An experiment was therefore conducted in which subjects debated the issue of capital punishment without regard for (or indeed knowledge of) the strictures of DC (Moore 1993). 
A set of evaluative criteria were developed, and the dialogues resulting from the DC experiment and the unconstrained dialogue experiment were analysed against each (Moore 1993). In essence, the analysis suggests that the DC dialogues can be regarded as comparing favourably with unconstrained dialogue in terms of clarity of intention and commitment, coverage of issues and absence of fallacious argument. The analysis does, however, suggest two major concerns with the DC dialogues: the way questions are handled by the DC framework, and the initiative patterns that can result from adoption of the framework.

DC permits only bipolar questions such as "is it the case that $P$ ?" and insists that the answer be one of "P," "not-P" or "no commitment to $P$." That the restricted range of question types may be problematic is suggested by the use of "illegal" question types in the protocols from both DC and unconstrained dialogues. Further, ineligibility of qualified answers to questions was seen as a deficiency by some subjects in the DC experiment. Mackenzie's acknowledgement that the question locution is crude (e.g. Mackenzie 1979b) appears therefore to be supported by the evidence.

The problem may not be as great as it at first sight appears, however. In terms of question response, one simply replies in line with one's actual or potential commitments; if one is not prepared for the commitment, the no commitment option should be chosen. It might be felt that this latter option would short-change both participants, in that having to use no commitment may make it harder for answerer to make his point, and harder for questioner to find out answerer's views on it. The latter problem, however, can be circumvented via challenge, or a statement to the effect that "I do not understand why you cannot commit yourself'. The former problem is not so readily soluble, in that the ability to expand one's view is contingent upon getting the initiative and/or being challenged on it; the absence of any challenge, however, would suggest that respondent would be placed under no disadvantage by the non-committal answer. Similarly, if respondent wants to respond "P because Q" to the question "is it the case that $P$ ?", he should respond "P" and wait for a challenge to give his grounds for $P$ (in this case $Q$ ). Absence of a challenge would suggest no strategic impoverishment by not being able to give such grounds.

Regarding the range of question types available, it could be argued that the only questions that have the right to a place in a debate as such are questions about the commitments of the participants - what they are already committed to or are prepared to commit themselves to. And this is precisely what the DC question type allows. All questions dealing with the "outside world", e.g. the comparative number of murders in UK and USA, are issues outside the debate per se-the debate is suspended while the truth of the empirical matter is investigated. In a similar way, in a computerised system, the debate may be suspended while "note cards" on the machine are consulted. Further, although the experiment with unconstrained dialogue contained a number of non-DC question types, it turns out that most can be "translated" into an equivalent DC-acceptable form (cf. Moore 1993). The restriction to bipolar questions need not therefore, in a computer context, lead to impoverishment. 
The second major concern with the DC dialogues revealed by the experiments involves the presence of relatively stable initiative patterns. The tendency was for one subject continuously to ask questions or make challenges, with his interlocutor able only to respond. The evidence suggests, however, that in a computational environment, initiative will largely reside with the student, and on Girle's argument (1986) this may be seen as a good thing, allowing the student to probe critically for information rather than act as a passive receiver. Further, heuristics can be devised that will prevent the computer from unreasonably retaining the initiative, on those occasions when it no longer resides with the student.

In sum, the qualitative assessment of debates generated via the dialectical system DC suggests that the system can be regarded as a valid prescriptive framework for useful educational dialogue. The comparison with dialogue generated without any DCimposed restrictions suggests that the qualitative differences between the dialogues produced by the two paradigms are in practice relatively little: most of the apparent restrictions in DC can be overcome, and DC avoids some difficulties that can beset unconstrained dialogues.

\subsection{Strategy in DC}

DC provides a regulatory framework within which dialogue participants must operate, but in common with other such frameworks, it allows room for participant discretion as to the precise operation of the system. In the case of DC, what might be considered its main asset, the simplicity engendered by its relatively slender rule set, may also be its downfall, for the cost of the simplicity is a reliance on the strategic wisdom of the participants, for example to maintain relevance. Further, the avoidance of unscrupulous yet legal play, e.g. constantly retracting and reasserting a proposition, must also rely on the strategic wisdom of the participants (cf. Mackenzie 1980).

Since the results from the previous section suggest that the generated dialogues can be considered qualitatively acceptable, this reliance on strategy seems justified. From the computational point of view, however, an understanding of the strategies adopted becomes vital. The computer will also follow DC's slender rule set, and it will be equally reliant therefore upon appropriate strategic wisdom. Indeed, the ability to capture this wisdom could be seen as the crucial aspect of the current research. For in this strategic knowledge lies the potential for a link between the logic of argumentation, as modelled by DC, and the semantics of discourse. And without this link, it might be suggested, $\mathrm{DC}$ will add nothing to currently available computer dialogue systems. It could be argued, against this suggestion, that $\mathrm{DC}$ would potentially be of value even without such a link. For it is possible for locutions to be syntactically correct and semantically meaningful, yet inappropriate at the pragmatic level. Were DC to provide a reasonable framework for debate at this pragmatic level, it would still have merit, even though it might in itself give no guidance in regard of the semantic content of the constituent moves in the debate. Nevertheless, the case for the adoption of $\mathrm{DC}$ would be considerably strengthened were a link to the semantics to exist 
or to be forged. For the upshot of the argument would be (at best) that DC is a pragmatic controller awaiting development of a suitable semantic processor to provide things for it to control. This would be cold comfort to anyone awaiting a working debating program. Further, one possible weakness of DC is that the system is largely neutral vis-à-vis focus and content considerations. That this has not turned out to be a problem has been seen as a result of participants' strategic reasoning, and this reliance on strategy again involves a link to discourse semantics.

It should be noted that any link to the discourse semantics forged via such strategic decisions is largely an extra-game consideration: all DC does is legitimise a set of move types given the prevailing circumstances, and occasionally give some indication of the semantic possibilities. One might think that DC would indicate what is legally available, a strategic choice would be made from this range, and the choice would then be 'filled up' with semantic content. Such a view would be too simple, however, for the strategic decision is likely to rely heavily on the available content, and a strategic decision may be needed between alternative contenders for the content (different supporting evidence, for example). In a computerised system, some interplay between strategic and semantic components may therefore be needed. The task is, therefore, to analyse the DC data with a view to deriving guidelines (heuristics) which will help a move maker select a sensible move. The formalisation attempt can be expected to reveal the nature of the strategy-semantic interplay, and thus to move towards a link between DC and discourse semantics, and hence towards computational dialogue participation.

Analysis of the game's properties makes it clear that at any stage in the game each participant has a double choice to make, concerning move type and semantic content. Further, at any stage in the game, one participant must be regarded as "having the initiative", in that no constraints are placed upon his choice of move type and content by his partner's previous move. At any given stage of the game the initiative must rest with one or other of the participants. The strategic problem is simpler for the participant who has not got the initiative. For choice of move type is more constrained - a question must be answered, a chalienge must be responded to by support, withdrawal, or (occasionally) resolution demand, and a resolution demand must be resolved. The content issue is heavily constrained following a question, concerns which statement to withdraw following a resolution demand, and is (in principle) totally unconstrained following a challenge. When a participant has the initiative, his strategic options are wider, since he has no constraints on move type and very few on content. There are three conditions in which a participant has the initiative: beginning of game, partner has used the No Commitment move type, partner has made a statement.

Now, it can be suggested that there are decisions at three levels, some or all of which are involved in a participant's strategic decision as to his next move. At level 1 the issue is whether (a) to retain the focus or (b) to change it. "Retain the focus" can be taken to mean continuing the same line of argument, which will involve continuing to attempt to substantiate or undermine a particular proposition. A decision at level 1 
is needed only where participant 1 (call him "P") has the initiative, since otherwise the game rules impose on $P$ the obligation to address his partner's previous move (call P's partner "O"). Where a decision is needed, one might intuitively expect there to be a presumption in favour of addressing partner's previous utterance (and therefore retaining the focus). In general, were the presumption in favour of addressing partner's previous utterance not to hold, conversations would be highly disjointed. And empirical analysis of the DC data shows that where the maker of the move has the initiative, he opts to continue the line of argument in the majority of cases, and usually to address directly his partner's previous move. Indeed, the decision at this level will often be pre-empted by the heuristic adopted at the previous turn. For example if the subject previously challenged with a view to rebutting arguments, he is inevitably likely to want to address the forthcoming reasons.

At level 2 there are again two alternatives for P. He can seek to demolish O's position, that is seek to have him remove from his CS propositions which he has used to support his thesis. This may be done either by showing a contradiction between, or an unacceptable consequence of, his $\operatorname{CS}$ (this may initially involve adding to $O$ 's store), or by demonstrating that he has no reasonable support for propositions in his CS. The ultimate aim is to remove all support of O's position. Alternatively, he can build his own position, by making statements the acceptance of which, or asking bipolar questions the answers to which, ultimately imply the truth of his thesis. Level 2 , like level 1 , will be by-passed if $P$ does not have the dialogue initiative. Further, the level 2 decision is needed only at the beginning of the game, and on those occasions when the level 1 decision is to change focus. As long as the level 1 decision retains the current line of argument, the decision between build or demolish made at the beginning of that line will continue. Empirical analysis of the DC data yields insufficient evidence to suggest heuristics re the beginning of games. Similarly, the evidence with regard to level 2 decisions after focus shifts is somewhat conflicting, in that the protocols contain evidence both of subjects desiring to build up stocks of commitments, and of subjects desiring to demolish their opponent's support of his thesis. There appears therefore to be no clear preference for either option at level 2 , implying that the computer would be on safe ground whichever it chose.

At level 3 the decision involves which method to adopt in fulfilment of the objective set at levels 1 and 2 . If $P$ is building he may form a plan, consisting essentially of a set of propositions he needs to add to O's CS, which ultimately combine to imply the truth of P's own thesis; similar plans, targeted at propositions $\mathrm{O}$ is using to support his thesis, could be used in demolition attempts. The plan can be activated at level 3 either by stating the first proposition in the plan, or posing a bipolar question with the proposition as its content. If the response is the one hoped for (e.g. O replies in the affirmative), $P$ can be expected to continue on to the next proposition in the plan (a level 1 decision). If the response is not what was hoped (e.g. O answers in the negative, or objects to the proposition), some level 3 mechanism will be needed for dealing with this response, assuming that the decision at level 1 is to continue with the line of argument. 
The following heuristics for level 3 have been derived from the evidence:

if a question has been asked:

answer in such a way as to avoid unwelcome commitments;

give answers for which good reasons can be given;

answer truthfully.

if a challenge has been made:

here one would normally reply with some support, but it is not clear from evidence so far collected how particular supports are chosen.

if a resolution demand has been made:

(tentatively proposed): withdraw whichever conjunct is the least harmful.

if a no commitment move has been made:

in the event of partner withdrawing a proposition previously used in support of his thesis, either check whether partner retains adherence to the thesis, and challenge for further reasons, or switch focus;

(tentatively proposed): in the event of withdrawal of a proposition at a lower level of a support hierarchy, seek withdrawal of propositions supported by that proposition.

if a statement has been made:

if there is (an expressed) contradiction in partner's CS, resolve it;

if there is any evidence directly contradicting any of partner's statements, state it;

seek substantive objection to partner's commitments, and pose questions with a view to making partner accept that objection;

seek out by challenge partner's arguments, with a view ultimately to rebutting them.

Note that the heuristics for dealing with a statement are listed here in the preferred order of choice. That is, if $O$ has commitments which $P$ wishes to dispute, the first heuristic would be the strongest method of attack for $P$, the fourth the weakest. The fourth might be regarded as an attack in itself, or as a means of elucidating O's reasoning with a view to further, more direct attack (via one of the other heuristics).

\section{DC as a computational model}

A user interface has been developed, by Hintze (Hartley and Hintze 1990), that allows two players to engage in a DC dialogue supported by a computer-based gameboard and referee. An example of the system ready for use is shown in Figure 1. (next page). The interface allows a user to select, from a menu, a move type from the range allowed by DC. The user then types in the content of their move. The system has no knowledge of the semantics of the players' moves, but is able to compute the logical connections between statements made, and thus decide what must go in each player's commitment store, and rule as to whether the move is legal. Commitment stores are displayed in "commitment set" windows. Participants are thus relieved of the cogni- 


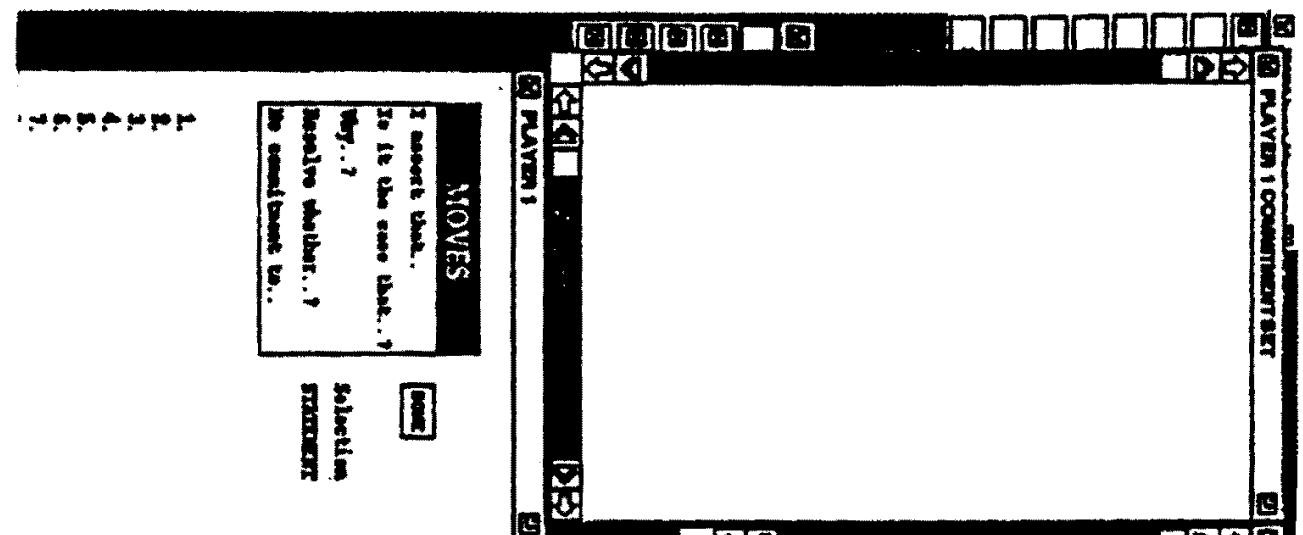

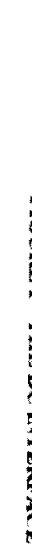
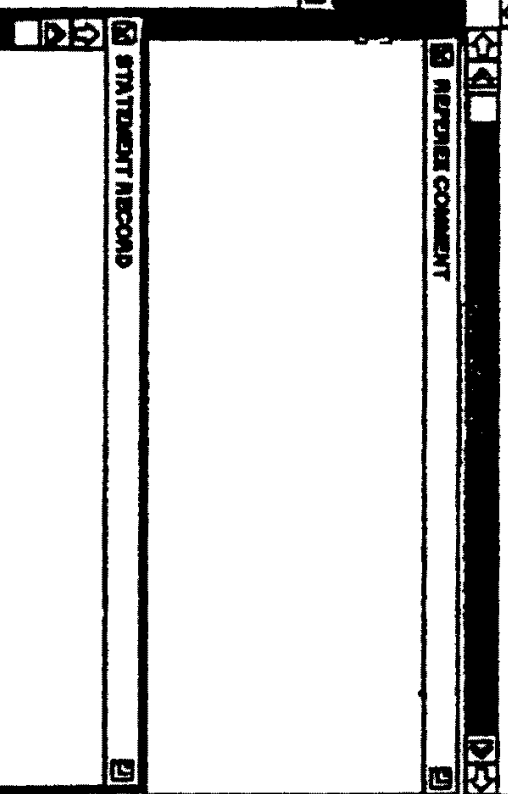

aDs0

.

본

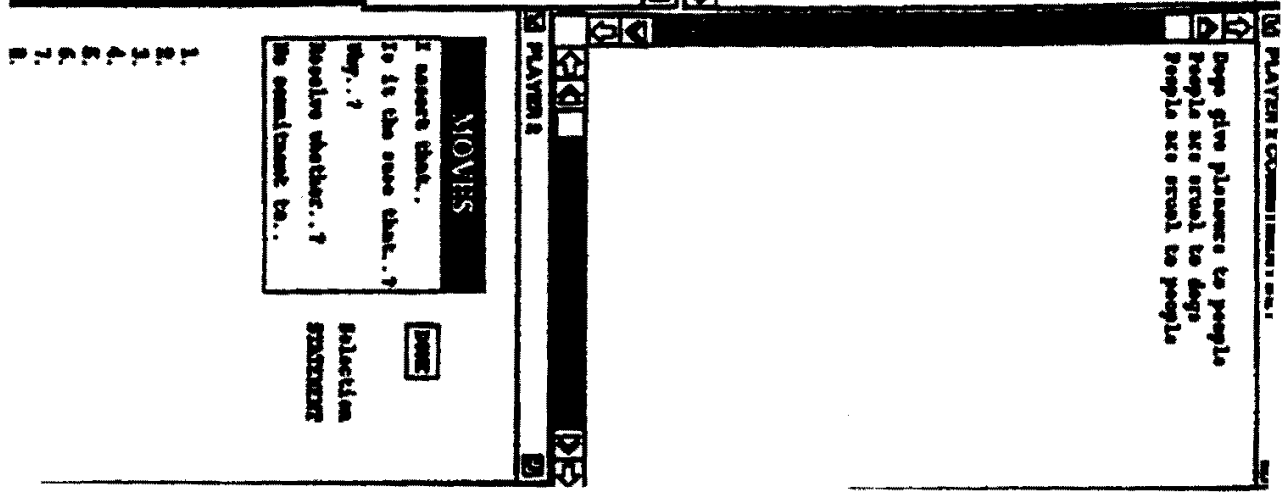


tive burden of commitment store recall. The interface is able to referee all moves made according to DC's dialogue rules, thus ensuring a legal debate.

Certain educational advantages of the use of this dialogue game interface can be suggested. It could be used as a spur to develop arguments logically, to remain consistent, and to improve debating skills. Using the interface with different dialogue partners forces application of these skills to information offered by the other player, thus potentially generating new insights into the domain of enquiry. The system offers the facility to record dialogues, and to replay previous dialogues either in full or to some specified point, from which users may continue to add their own contributions. Thus dialogues from different participants can be studied, and alternative lines of thought experimented with.

Indeed, the successful implementation of the DC interface is all that is required to demonstrate the computational tractability of DC as a dialogue model. For DC is seen as a framework through which two people can engage in dialogue with each other, by adhering to certain rules, and by being made accountable, via their commitment stores, for what they say and accept during the debate. And the DC interface provides precisely such a vehicle. It thus provides a computerised version of the DC system, and demonstrates DC's computational tractability. Of more educational interest, however, is the possibility of having the computer act as a participant in the dialogue. This will involve enabling the computer to make its own contributions, as well as acting as referee and administrator of the debate.

Such a system will be required to take part in, and referee, debates with individual students. The computer (C) would therefore seek the student's (S's) opinion on a controversial subject, e.g. capital punishment, inform the student of its own (opposing) view, and invite $\mathrm{S}$ to participate in debate on that subject. During play $\mathrm{C}$ will need to recognise the type and content of S's moves, and to rule as to their legality. Assuming the move is deemed legal, the commitment stores of both $\mathrm{S}$ and $\mathrm{C}$ may need to be updated, and the dialogue history updated. All these requirements are met by the current DC interface. Next, $C$ needs to select a suitable move type and content with which to respond to S's move, and to arrange for the move to be displayed to S. S in turn makes his response, causing the cycle to start again, until one or other party either "wins", or withdraws through lack of time or interest. A software architecture for a system to fulfil these requirements has been designed, and is the subject of ongoing research and development work (Moore 1993).

One difficulty with the proposed system concerns knowledge representation, widely seen as the central issue in AI in general (e.g., Bench-Capon 1990), and ITS in particular (e.g., Yazdani 1986). In the current context the challenge is to represent the system's domain knowledge in such a way as to enable provision of statements that can be used in response to questions, and of statements that can be used to support other statements. Satisfaction of these two requirements will provide the knowledge to enable $\mathrm{C}$ to operationalise the strategic heuristics discussed earlier. For example, demolition attempts can be catered for by negating the proposition which is the target of 
the demolition, and recursively seeking to support that negation. Building attempts can be handled by recursively supporting the thesis itself. Starting at the "bottom" (i.e. with the last proposition to be returned) would yield a "distancing" strategy; the first support statement generated would form the strategy's "corner" (Walton 1984). Both are analogous to Cohen's (1987) pre-order form of argument. If C is subject to a challenge from $\mathrm{S}$, it can respond with the first statement found in support of the challenged statement; in effect this resembles Cohen's post-order form of argument. If the proffered support is itself challenged, $\mathrm{C}$ can use the next in the recursive line of support. An alternative method of responding to challenge would be recursively to apply the support relationship, and offer as support the last statement found; this would in effect leave many enthymematic premises, which $\mathrm{S}$ could uncover by further challenges.

One way of engineering the knowledge base to fulfil these requirements is provided by Bench-Capon et al. (1990). They utilise a modified version of Toulmin's argument formalism to construct a knowledge base which can be used by an interpreter to generate, on-line, paragraphs of text. In the current context the idea would be to use the output from the interpreter as the basis for responses to user challenges, using the appropriate "data" or "warrants" relating to the claim that has been challenged. Such an arrangement would enable a generic knowledge base to be held, and is discussed further in (Moore 1993).

Another interesting approach to the issue of retrieving appropriate information from the knowledge base is to draw upon work using "rhetorical predicates" (Grimes 1975) to generate coherent text at the paragraph level or beyond (Pilkington 1992b). Rhetorical predicates have been used successfully in a number of computer-based implementations (see, e.g., Tattersall 1993, Maybury 1992). The knowledge-base can be represented in a generic or "pure" manner (Pilkington 1992b), with predicates abstracting out the appropriate content for a particular utterance (Maybury 1992). This would enable different domains to be accessed by the debating system, thus providing debates across a range of issues. An extended example of the use of rhetorical predicates in a dialogue game context is provided in Pilkington et al. (1992).

The use of rhetorical predicates also offers a potential solution to a second major difficulty with the proposed system, the handling of substantive student input. Computer processing of free range natural language input is a large problem (e.g. Allen 1987), beyond the scope of the current project. It may be possible, however, to use rhetorical predicates as an intermediary language, forming a level between the system's semantic domain representation and the user interface. The idea is that the predicates are iconised and the student uses them in the cut-and-paste construction of his substantive moves. In this way the student can construct relationships between objects, to form the propositional content of his moves. He may, for example, select a cause-consequence predicate, and objects "angina" and "fatigue", to suggest that angina can give rise to fatigue. In this way the system can provide a range of semantic links which can give rise to a common understanding between system and user. The 
system can then test for consistency between relationships and objects proffered by the user, and existing relationships and objects in the domain knowledge base, and decide, on this basis, whether to accept the statement or to seek to demolish it via the strategic heuristics. Indeed, it may be that in certain circumstances, the domain knowledge base itself should be altered as a result of relationships suggested by users, so that a learning element can be incorporated into the system (cf. Pilkington et al. 1992).

\section{An example}

An attempt will now be made to give a brief overview of a conceptualised system operating with the topic of debate concerning whether all dogs should be exterminated. The discussion here will assume the idea of using hypertext-like cards, with links based on Bench-Capon et al.'s argument schema. The discussion should both illuminate the workings of the card-based approach, and the ability of the DC framework and strategic heuristics to operate to produce debate.

The card-based approach assumes that a set of inter-linked cards can be created. This may be done by the system designer, or by some domain "expert", or, in a school setting, by a member of the student body, since the creation of the resulting conceptual map might itself be of educational benefit. A starting point is likely to be the creation, perhaps by a brainstorming session, of a number of (possibly) relevant propositions. In this case suitable propositions might be:

dogs protect people

dogs help people

dogs give amusement

dogs foul pavements

dogs bite people

dogs use up resources

dogs can be guide-dogs for the blind

dogs can help round up sheep

dogs can guard property

dogs are a popular pet

making dog food provides employment

unwanted dogs are turned loose in the street

dogs must be registered

people are cruel to dogs

dogs eat food

people can be prosecuted for not looking after dogs

RSPCA looks after dogs' interests

Having collected a preliminary set of propositions, these need to be linked in accordance with the model of argumentation being adopted. In this instance a simplified version of the Bench-Capon $e t$ al. model will be used, in which only the evidence and rebuttal links are used. The latter will be treated as a straightforward candidate 


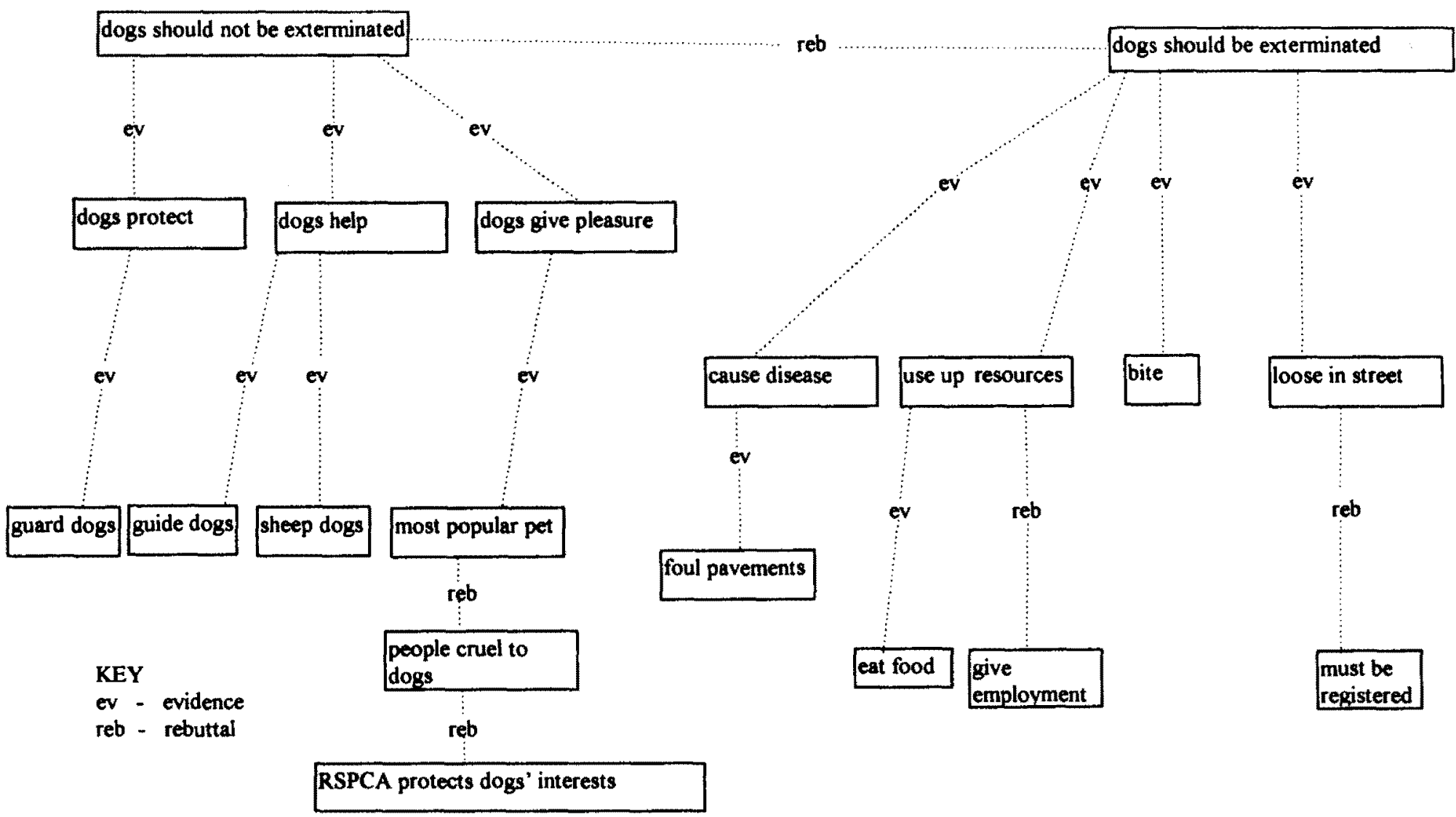

Figure 2 - Conceptual Map of the Dog Domain 
"objection", since the "unless" construct, for which it was originally intended, is not available in DC.

There are many ways in which the propositions can be linked. This is a necessary condition of, and part of the reason for, debate in the first place; people with identical conceptual maps cannot have a meaningful debate. The representation in Figure 2 (opposite) is, therefore, a suggested representation only. Given this conceptual map of the dog domain, an analysis of how a computer (C) might hold a debate with a student $(S)$ can be presented. The following debate will be traced on a line-by-line basis.

$1 \mathrm{C}$ Is it the case that dogs should be exterminated? (S1?)

2 S NotS1.

$3 \mathrm{C} \quad$ Dogs should be exterminated. (SI)

$4 \mathrm{~S} \quad$ Why S1?

$5 \mathrm{C}$ Dogs cause disease. (S2)

$6 \mathrm{~S}$ Why $\mathrm{S} 2$ ?

$7 \mathrm{C}$ Dogs foul the pavement. (S3)

$8 \mathrm{~S} \quad$ Why S3 $\rightarrow \mathrm{S} 2$ ?

$9 \mathrm{C} \quad$ No commitment to $\mathrm{S} 3 \longrightarrow \mathrm{S} 2$.

$10 \mathrm{~S}$ Why $\mathrm{S} 2$ ?

$11 \mathrm{C}$ No commitment to $\mathrm{S} 2$.

$12 \mathrm{~S}$ Dogs give pleasure to people. (S4)

$13 \mathrm{C}$ Why $\mathrm{S} 4$ ?

$14 \mathrm{~S}$ Dogs are the most popular pet. (S5)

15 C People are often cruel to dogs. (S6)

$16 \mathrm{~S}$ The RSPCA protects dogs' interests. (S7)

$17 \mathrm{C}$ Is it the case that dogs eat food? (S8?)

$18 \mathrm{~S}$ S8.

$19 \mathrm{C}$ Is it the case that dogs use up the world's resources? (S9?)

$20 \mathrm{~S}$ S9.

$21 \mathrm{C} \quad$ Is it the case that $\mathrm{S} 9 \rightarrow$ dogs should be exterminated?

$22 \mathrm{~S} \quad$ Not $(\mathrm{S} 9 \rightarrow$ dogs should be exterminated).

$23 \mathrm{C}$ Why?

$24 \mathrm{~S}$ Making of dog food provides employment.

Lines 1-3 can be regarded as setting up the game's preconditions, with $\mathrm{C}$ taking, at line 3 , the opposing thesis to S. At line $4 \mathrm{~S}$ challenges C's thesis. This is done by selecting "Why..." from the move menu in the DC interface, and S1 from the statement record. This suffices to tell $\mathrm{C}$ that a challenge has been made, and the heuristics suggest that a statement is required in response. $\mathrm{C}$ therefore searches the cards for any which have an "evidence" link to the challenged proposition; any such will be a candidate for the statement to be made. In this case there are four such candidates ("dogs cause disease", "dogs bite people", "dogs are often loose in the street", "dogs use up the world's resources"), but it can be assumed that $C$ will use the first appropri- 
ate card it finds, and that in this case the "winner" is "dogs cause disease". This is therefore posted as C's move (line 5). Identical reasoning causes C's response in line 7 to S's challenge at line 6 . At line 8, S takes the option of challenging the implication concomitant upon C's move at line 7. C again searches the card knowledge-base, but finds no card with an evidence link. The only available option therefore is to withdraw the challenged statement (line 9). Since there is no longer any support for $\$ 2$, this is again challenged (line 10); a search of the cards shows no suitable evidence link, so C must now withdraw S2 (line 11).

S now starts a build attempt (line 12). This is done by selecting "I assert that..." from the move menu, and "dogs give pleasure" from the card-stack. This stack should be available to $S$ in a separate "domain" window; the encoded links between the cards should not be shown to $S$, since this would detract from the requirement imposed on $S$ to build his own argument given the available information. $C$ is therefore aware that a statement has been made. All three levels of strategic decision making are therefore applicable. Since there is a presumption at level 1 in favour of addressing the previous utterance, and since there is nothing here to suggest otherwise, $C$ will address S's utterance. Since there is an evidence link from S's chosen card to S's thesis, this level 1 decision implies in this case that the level 2 decision must be in favour of demolition, and that the preferred order of heuristics is:

(a) If there is (an expressed) contradiction in S's commitment store, resolve.

(b) If there is any evidence directly contradicting any of S's commitments, then state it.

(c) Seek substantive objection to any of S's commitments, and pose questions with a view to making $S$ accept that objection.

(d) Seek out (by challenge) S's arguments, with a view ultimately to rebutting them.

Examination of S's commitment store reveals that (a) is not available (the store contains no contradiction). The only statement in S's store, apart from his thesis, is the one just made, and since there is no card with a "rebuttal" link to this statement, heuristic (b) must be ruled out. Similarly, there is no evidence for the negation of S's statement, so that heuristic (c) also fails. Heuristic (d) must therefore be utilised (line 13). $S$ replies by suggesting that dogs are the most popular pet (line 14).

S's selection of the statement move type implies that all three levels of strategy again need to be considered. The default condition at level 1 applies (since $\mathrm{S}$ has responded to C's challenge), and level 2 is therefore redundant. C therefore needs to consider the same set of heuristics as on its previous move. Heuristic (a) is again unavailable, but since a rebuttal is present in the card knowledge base, heuristic (b) does fire, and $\mathrm{C}$ makes a statement of the rebuttal (line 15). $\mathrm{S}$ finds a card to use as rebuttal of the rebuttal (line 16).

$\mathrm{C}$ needs to respond to this statement. The knowledge-base contains no rebuttal to S's statement, and no evidence for the statement's contradiction, and since the use of a challenge would lead to either a complex line of argument or a non-committal re- 
sponse, the level 1 decision is to change focus. Given an assumption in favour of building, $C$ needs to seek suitable support of its own thesis ("dogs should be exterminated"). This can be done by seeking cards with evidence links to this thesis. Assume that $C$ will adopt the first (unused) such card, and that in this instance the card "dogs use up the world's resources" is found. Evidence for this, in order to mount a distancing strategy, will also be sought, and so on recursively. In this instance the loop ends with the next card ("dogs eat food"). The level 3 decision therefore recommends posing this as a question (line 17). At line $18 \mathrm{~S}$ answers in the desired way, so the next stage in the distancing plan is selected, and the question put (line 19), to which $S$ again acquiesces (line 20). C therefore asks what in effect would be the victory question (line 21), but does not get the response sought. The level 3 heuristics therefore fire against unwanted response, (d) is the only one applicable, and the challenge is made (line 23), to which S replies in line 24.

This example (which could of course continue) shows that the idea of utilising a hypertext style approach based on Bench-Capon et al.'s argumentation model, can furnish appropriate content for the dialogue moves. Although not shown in the example, the links between the cards could be used by $C$ when electing how to respond to questions, resolution demands, and withdrawals for $S$. Further, the computer could have argued the case against the extermination of dogs, thus permitting debate to take place irrespective of whether the initial position of $S$ is for or against canine extermination. The example also shows that the rules and strategies are generic, in that a set of cards relating to a different domain could be used, with no requirement to alter the dialogue rules or strategic heuristics.

The card-based approach also provides a short-term answer to the input problem. The contents of the cards can furnish S's substantive moves, and a blank card would be available to cater for $\mathbf{S}$ disenchantment with those on offer. Further, by tracing the links between cards selected by $\mathrm{S}, \mathrm{C}$ can interpret them as being favourable or unfavourable to its own position, and thus decide whether they form sensible objects of attack. A potential difficulty in this context might arise if $S$ uses cards in ways which run counter to the encoded links, using as support of his position, for example, cards which have evidence links to C's thesis. In this case the best that can be suggested, perhaps, is that $\mathrm{C}$ challenge the use of the card (i.e. challenge the implication of which it forms the antecedent). Substantive $S$ response will necessitate abandoning the current line of argument, and subsequent knowledge-base reconsideration by its "author", Similarly, $\mathrm{S}$ may not accept that a proposition (P) used by $\mathrm{C}$ as defence of a further proposition $(\mathrm{Q})$, should rightfully be so used. The issue is again one of disagreement with the accuracy of the conceptual domain map. In such circumstances, $\mathrm{S}$ should challenge the proposition's status as evidence (as in line 8). $\mathrm{C}$ will not be able to defend itself, and must therefore withdraw the statement; $\mathrm{S}$ will not therefore be disadvantaged by any refusal to accept the conceptual map. In the longer term, the knowledge base author may wish to strengthen the knowledge base by inserting (what is seen as) suitable support for the evidence relationship; this would be equivalent to 
Bench-Capon et al.'s "warrants" (1990). Similar arguments apply to S's disagreement with alleged rebuttal relationships between propositions.

Summarising, the analysis in this section has followed the workings of a conceptualised system as it seeks to utilise the strategic heuristics in order to participate in debate. Current work involves a developing a full implementation of the system. A problem implicit in the discussion concerns the notion of relevance. Following Carlson (1983), relevance is seen as a strategic concern, and it could be argued that, as far as the computer's contributions are concerned, relevance is provided by the heuristics, given appropriate service from knowledge base. It might also be contended that relevance of $S$ input could be taken for granted, since $C$ would assume rationality on S's part. A difficulty arises, however, in the case of genuine irrelevancies, for were $\mathrm{C}$ to fire the heuristics against these, rather than ignore them, the debate could spend some time in a wholly inappropriate direction. Nevertheless, since $C$ has no means of distinguishing clever strategy from time-delaying or attempts to psyche out the machine, it will need to assume a co-operative user, and treat all inputs on merit.

A co-operative user also needs to be assumed in connection with the resolution demand move type. For by leaving the list $(V)$ of preferred valid argument schemata unspecified, and always withdrawing following a legal resolution demand, $C$ is open to false accusations of inconsistency, and, worse, may confuse the genuine student by withdrawing commitments which are not "really" inconsistent. This may be a problem in the short term, but is very unlikely to arise in practice, and, in the longer term, a specification for $V$ can be arrived at, leaving $C$ the possibility of an objection move where $V$ is not appropriately invoked. The converse danger, that $C$ can pose resolution demands concerning any statements in S's commitment store, can be avoided by allowing usage of resolution demand only in the face of direct inconsistency $(\mathrm{P}$, not- $\mathrm{P})$, and inconsistency involving modus ponens $(\mathrm{P} \rightarrow \mathrm{Q}, \mathrm{P}$, not- $\mathrm{Q})$.

\section{Conclusions and further work}

The research outlined in this paper represents a preliminary attempt to investigate the potential of DGT as a vehicle for enhanced human-computer communication. The investigation has involved empirical tests of the suitability of the DC system, and an enquiry into the tractability of the system for computer-based applications.

The overall conclusion from the research is that DGT would appear to offer a promising vehicle for computer-based dialogue. This has been demonstrated from both the computational and user viewpoint. From the computational point of view, the demonstration has been via discussion of an operational dialogue game interface, and the construction of a suitable architecture for, and program conceptualisation of, computational participation in dialogue, utilising the simplicity and order imposed on dialogue via the game moves and rules, a set of heuristics, and previous successful work on argument schemata (cf. Bench-Capon et al. 1990) to access knowledge based systems. From the user's point of view, there is a trade-off, as in all computer applica- 
tions, between the difficulty of adopting the system's strictures, and the advantages to be gained by so doing. Adapting to DC's regimen has been shown to impose a relatively light cognitive load on users, and the computer interface liberates players from many of the game's potential complexities. Given this, and the advantages of the enhanced dialogue that DC allows, the trade-off seems favourable: the potential gain is sufficient to merit the effort required to adopt the system. In brief, it has been shown that $D C$ provides the tightness of dialogue needed for computational tractability, whilst still being advantageous from the user's point of view.

There are a variety of interesting ways in which the research can be carried forward. In the short term, the aim will be to develop further the debating system, to yield an application which adopts a position diametrically opposed to that of the student, and engages him in debate. Interesting enhancements to this "basic" debating system can be suggested. One is to extend the system to use interactive video and other multimedia technology (Hobbs and Moore 1994). One use for video might be as an initial stimulus to encourage students to enter debate, showing, for example, a documentary about abortion, or footage of philosophers in discussion. The computer could also use, where appropriate, video as its contribution to the debate, in the manner of DECIDER (Bloch and Farrell 1988). Interesting questions would then arise as to how to select the best form of output (cf. Du Boulay and Sloman 1988). A further advantage of multimedia technology would be to provide, via hypermedia links highlighted in the computer's output, opportunities for the student to clarify points and/or terminology he does not understand (Bielawski and Lewand 1991). Such a hypermedia facility could be expected to ease the lack of a clarification move in DC. Such developments suggest that the debating system could eventually find a place in an overall "study station" (Tait 1987), with the debate and other facilities operating to each others' (and therefore, of course, to the student's) mutual advantage.

A long term goal will be to move beyond debate, into other forms of dialogue interaction. The ultimate goal would be a system capable of selecting and engaging in a variety of interaction styles with students, according to the demands of the subject matter and the educational interests of the individual student. It is clear that many interesting and challenging issues need to be addressed, concerning in particular the development of suitable dialogue models, and computational utilisations thereof, before this goal can be reached. However, this paper hopes to help bring together two groups of workers (philosophers of dialogue and designers of ITS) so that each can learn from, and contribute to, the experiences of the other, and thus move towards achieving that goal.

\section{Acknowledgement}

The authors gratefully acknowledge Professor J. Roger Hartley, Dr. Rachel Pilkington, and David Hintze, for many invaluable discussions in connection with this work. 


\section{References}

Allen, J. (1987). Natural Language Understanding; Benjamin/Cummings.

Anastasi, A. (1982). Psychological Testing. MacMillan.

Bailey, J.J. (1989), Explanation-Giving Systems for Learning Decision-Making Skills. Ph.D. Thesis, Computer Based Learning Unit, School of Education, University of Leeds.

Baker, M. (1989). A model for tutorial dialogues based on critical argument. In D. Bierman, J. Breuker and J. Sandberg, (eds.), Arificial Intelligence and Education, Proceedings of the Fourth International Conference on Al and Education: 24-26.

Baker, M. (1994). A Model for Negotiation in Teaching-Learning Dialogues. Journal of Artificial Intelligence in Education, vol. 5, no. 2: 199-254.

Barth, E.M. (1982). A Normative-Pragmatical Foundation of The Rules of Some Systems of Formal Dialectics. In Barth and Martens (1982).

Barth, E.M. and Krabbe, E.C.W. (1982). From Axiom to Dialogue: A Philosophical Study of Logics and Argumentation. Walter de Gruyter.

Barth, E.M.and Martens, J.L. (Eds.). (1982). Argumentation: Approaches to Theory Formation. John Benjamins, B.V.

Bench-Capon, T.J.M., Lowes, D.and McEnery, A.M. (1990). Using Toulmin's Argument Formalism to Explain Logic Programs. Proceedings Explanations Workshop V, Manchester.

Bench-Capon, T.J.M. (1990). Knowledge Representation. Academic Press.

Bench-Capon, T.J. M., Dunne, P.E.S. and Leng, P.H. (1991). Interacting with Knowledge Based Systems through Dialogue Games. Proceedings of Eleventh International Conference, Expert Systems and their Applications, vol. I. Avignon, May 1991.

Bielawski and Lewand. (1991). Intelligent Systems Design. Wiley.

Bloch, G., Farrell, R. (1988). Promoting Creativity Through Argumentation; DECIDER: a case based teaching system. ITS-88: 243-249.

Booth, P. (1989). An Introduction to Human-Computer Interaction. Lawrence Erlbaum.

du Boulay, B.and Sloman, A. (1988). Bread Today, Jam Tomorrow: The Impact of AI on Education. Proceedings of Fifth International Conference on Technology and Education, vol. $1: 82-85$.

Carlson, L. (1983). Dialogue Games : An Approach to Discourse Analysis. D. Reidel.

Carlson, L. (1984). "Well" in Dialogue Games. John Benjamin.

Carlson, L. (1984b). Focus and Dialogue Games. In L. Vaina and J. Hintikka (eds.), Cognitive Constraints on Communication, pp. 295-333. D Reidel.

Cawsey, A. (1990). A Computational Model of Explanatory Discourse: Local Interactions in a Plan-Based Explanation. In N. Luff, (ed.), Computers and Conversation. Academic Press.

Clark, H.H., Schaefer, E.F. (1989). Contributing to Discourse. Cognitive Science 13: 259-294.

Cohen, R. (1987). Analysing the Structure of Argumentative Discourse. Computational Linguistics, vol. 13 numbers 1-2: 11-24.

Elsom-Cook, M. (1985). Towards a Framework for Human-Computer Discourse. In P. Johnson and S. Cook, (eds.), People and Computers: Designing the Interface. Cambridge University Press. 
Elsom-Cook, M. (1988). Guided discovery learning and bounded user modelling. In Self (1988).

Finkelstein, A. and Fuks, H. (1990). Conversation Analysis and Specification. In N. Luff, (ed.), Computers and Conversation. Academic Press.

Finkelstein, A. and Fuks, H. (1989). Multi-Party Specification. Proceedings Fifth International Workshop on Software Specification and Design. Pittsburgh.

Frohlich, D.M.and Luff, P.(1990). Applying the Technology of Conversation to the Technology for Conversation. In N. Luff, (ed.), Computers and Conversation. Academic Press.

Fuks, H, Ryan, M. and Sadler, M. (1989). Outline of a Commitment Logic for Legal Reasoning. Proceedings of Third International Conference on Logic, Informatics, Law.

Galton, M. and Simon, B. (Eds.). (1980). Progress and Performance in the Primary Classroom. Routledge and Kegan Paul.

Garrison, D.R. (1991). Critical Thinking and Adult Education: A Conceptual Model for Developing Critical Thinking in Adult Learners. International Journal of Lifelong Education, vol. 10, no. 4: 287-304.

Girle, R.A. (1986). Dialogue and Discourse. In G.Bishop and W. Van Lint, (eds.), Proceedings of the Fourth Annual Computer Assisted Learning in Tertiary Education Conference, Adelaide. Distributed by Office of Continuing Education, University of Adelaide.

Gordon, T.G. (1994). The Pleadings Game: An Exercise in Computational Dialectics. Artificial Intelligence and Law, vol. 2, no. 4: 239-292.

Grimes, J.E. (1975). The Thread of Discourse. de Mouton.

Hamblin, C.L. (1970). Fallacies. Methuen.

Hamblin, C.L. (1971). Mathematical Models of Dialogue. Theoria, vol. 37, no. 2: 130-155.

Hamblin, C.L. (1987). Imperatives. Basil Blackwell.

Hartley, J.R. and Hintze, D. (1990), Dialogue and Leamer Modelling. In S.A. Cheri, (ed.), Student Model Acquisition in a Natural Laboratory (NATLAB); GEC DELTA Project D1016 Final Report, Brussels.

Hartley, J.R., Pilkington ,R., Tait, K. and Tattersall, C. (1990). Question Interpretation and Answering. In J. Breuker, (ed.), EUROHELP: Developing Intelligent Help Systems; EC.

Hintikka, J. and Hintikka, M.B. (1982). Sherlock Holmes Confronts Modern Logic: Toward a Theory of Information-Seeking Through Questioning. In Barth and Martens (1982).

Hobbs, D.J. and Moore, D.J. (1994). Multimedia Open Leaming Systems in a New UK University. Proceedings of Interdisciplinary Workshop on Complex Learning in Computer Environments, Finland.

Hoepelman J, Machate J, Schnitzer R (1991) Intonational Focusing and Dialogue Games; in Journal of Semantics, vol. 8, part 3:253-275.

Jackson, P. (1990). Introduction to Expert Systems. Addison-Wesley.

Jeremaes, P. (1987). Specifying the Interface Logic. In H.J. Bullinger and B. Shackel, (eds.), Human-Computer Interaction INTERACT' 87 . Elsevier Science Publishers B.V.

Levin, J.A. and Moore, J.A. (1977). Dialogue - Games: Metacommunication structure for natural language interaction. Cognitive Science, vol. 1, part 4: 395-420.

Lorenz, K. (1982). On the Criteria for the Choice of Rules of Dialogic Logic. In Barth and Martens (1982). 
Lorenz, K. (1987). Meaning Postulates and rules of Argumentation: Remarks Concerning the Pragmatic Tie between Meaning (of Terms) and truth (of Propositions). In F.H. van Eemeren, R Grootendorst, J.A. Blair and C.A. Willard, (eds.), Argumentation: Across the Lines of Discipline. Foris Publications.

Mackenzie, J.D. (1979a). Question-Begging in Non-Cumulative Systems. Journal of Philosophical Logic: 117-133.

Mackenzie, J.D. (1979b). How to Stop Talking to Tortoises. Notre Dame Journal of Formal Logic, vol. XX, no. 4: 705-717.

Mackenzie, J.D. (1980). Why do we Number Theorems? Australasian Journal of Philosophy, vol. 58: 135-149.

Mackenzie, J.D. (1981). The Dialectics of Logic. Logique et Analyse, vol. 94: 159-177.

Mackenzie, J.D. (1984). Begging the Question in Dialogue. Australasian Journal of Philosophy, vol. 62:174-181.

Mackenzie, J.D. (1985). No Logic before Friday. Synthese 63: 329-341.

Mackenzie, J. (1990). Four Dialogue Systems. Studia Logica, XLIX, 4: 567-583.

Mann, W. (1988). Dialogue Games: Conventions of Human Interaction. Argumentation vol. 11: 511-532.

Maybury, M. (1992). Communicative Acts for Explanation Generation. International Journal of Man-Machine Studies, 37: 135-172.

Moore, D.J. (1993). Dialogue Game Theory for Intelligent Tutoring Systems. Unpublished PhD dissertation, Leeds Metropolitan University.

Mushrush, J.L. (1990). Options in Learning: Instructor led and CBT. Journal of Library and Administration, vol. 12, no. 2: 47-56.

National Curriculum Council. (1990a). Curriculum Guidance 7 -Environmental Education; NCC, York.

National Curriculum Council. (1990b). Curriculum Guidance 8 - Education for Citizenship; NCC, York.

O'Shea ,T, and, Self, J. (1983), Learning and Teaching with Computers: Artificial Intelligence in Education. The Harvester Press.

Parsons, M.W. (1985). Computers and Religious Education. In P.R. Smith, (ed.), Advances in Computer Assisted Learning, Proceedings from the CAL 85 Symposium. Pergamon Press

Pilkington, R.M. (1992a). Intelligent Help, Communicating with Knowledge Based Systems. Paul Chapman Publishing Ltd.

Pilkington, R.M. (1992b). Question-Answering for Intelligent On-Line Help: The Process of Intelligent Responding. Cognitive Science 16:455-489.

Pilkington, R.M., Hartley, J.R., Hintze, D. and Moore, D.J. (1992). Learning to Argue and Arguing to Learn: An Interface for Computer-based Dialogue Games. Journal of Artificial Intelligence in Education, vol. 3 no. 3: 275-295.

Reichman, R. (1985). Getting computers to talk like you and me: Discourse Context, Focus, and Semantics (An ATN Model). MIT Press.

Ridgway, J. (1988). Of Course ICAI is impossible - .... worse, though, it may be seditious. Self (1988). 
Self, J. (Ed.). (1988). Artificial Intelligence and Human Learning: Intelligent ComputerAided Instruction. Chapman and Hall.

Shiffrin, D. (1985). Lauri Carlson: Dialogue Games, An Approach to Discourse Analysis (review article). Language in Society, vol. 144: 98-100.

Shneiderman, B. (1992). Designing the User Interface - Strategies for Effective HumanComputer Interaction. Addison-Wesley.

Stenton, S.P. (1988). Dialogue Management for Co-operative Knowledge Based Systems. The Knowledge Engineering Review: 99-122.

Stewart-Zerba, L. and Girle, R. (1993). Rules and Strategies in Dialogue Logic. Proceedings of the Sixth Australian Joint Conference on Artificial Intelligence, Melbourne.

Tait, K. (1987). The Study Station Concept. University Computing, vol. 9:25-28.

Tattersall, C. (1993). Generating Help for Users of Applications Software. User Modelling and User-adapted Interaction: Special Issue on Natural Language Generation and Dialogue Planning. Kluwer.

Walton, D.N. (1984). Logical Dialogue Games and Fallacies. University Press of America.

Walton, D.N. (1985). New Directions in the Logic of Dialogue. Synthese, 63: 259-274.

Walton, D.N. (1989). Question-Reply Argumentation. Greenwood Press.

Woods, J. and Walton, D. (1982a). Argument: The Logic of the Fallacies. McGraw-Hill Ryerson.

Woods, J. and Walton, D. (1982b). Question-Begging and Cumulativeness in Dialectical Games. Nous: 585-605.

Yazdani, M. (1986). Intelligent Tutoring Systems Survey. Artificial Intelligence Review 1:43-52.

D. J. MOORE / D. J. HOBBES FACULTY OF INFORMATION AND ENGINEERING SYSTEMS LEEDS METROPOLITAN UNIVERSITY, BECKETTE PARK LEEDS LS6 $3 Q S$ UNITED KINGDOM 